\title{
A comparison of opioid-containing anesthesia versus opioid-free anesthesia using the Cortínez- Sepúlveda model on differential cytokine responses in patients undergoing gastric bypass surgery: a randomized controlled trial
}

Erika Martínez-López ( $\square$ erikamtz27@yahoo.com.mx )

University of Guadalajara

Wendy Campos-Pérez

University of Guadalajara

Lilia Ramírez-Plascencia

Civil Hospital of Guadalajara "Juan I Menchaca"

Mariana Pérez-Robles

University of Guadalajara

Juan J Rivera-Valdés

University of Guadalajara

Patricia Sánchez-Muñoz

Civil Hospital of Guadalajara "Juan I Menchaca"

Liliana Pérez-Vargas

Civil Hospital of Guadalajara "Juan I Menchaca"

Dulce González-Landeros

Civil Hospital of Guadalajara "Juan I Menchaca”

Juan Heberto Muñoz Cuevas

Civil Hospital of Guadalajara "Juan I Menchaca”

Research Article

Keywords: Opioid free anaesthesia, fentanyl, Cortínez-Sepúlveda model, IL-6

Posted Date: February 28th, 2022

DOI: https://doi.org/10.21203/rs.3.rs-1301535/v1

License: (c) (1) This work is licensed under a Creative Commons Attribution 4.0 International License.

Read Full License 


\section{Abstract}

Background: Anesthetic agents, including opioids can modulate the altered immune function in patients with obesity through mechanisms that involve the expression and release of cytokines. For this reason, anesthetic care in patients with obesity remains controversial. Therefore, the aim of the study was to compare the effect of opioid-containing anesthesia vs opioid-free anesthesia using the CortínezSepúlveda model on serum levels of IL-6, IL-1 $\beta$ and TNF- $\alpha$ before and after surgery in obese patients undergoing bypass surgery.

Methods: A randomized cross-sectional study of 40 unrelated obese adults was performed at the Civil Hospital of Guadalajara "Dr. Juan I. Menchaca”. Before undergoing laparoscopic Roux-en-Y gastric bypass, patients were randomly assigned to two anesthesia groups: opiod-containing $(n=20)$ or opiodfree $(n=20)$. The opioid used in the opioid-containing anesthesia group was fentanyl. To characterize the disposition of intravenous propofol for the target-controlled infusion technique in obese patients, the Cortínez-Sepúlveda pharmacokinetic model was used. Body mass was determined to the nearest $0.05 \mathrm{~kg}$ using a balance scale (Seca 703; Seca, Hamburg, Germany). Blood samples were taken before and immediately after surgery and cytokine serum levels were determined with ELISA kits. Pain was assessed using a numerical pain rating scale. Adverse effects were collected $24 \mathrm{~h}$ after surgery.

Results: 6 men and 34 women were included in this study (37.9 \pm 10.6 years). Pre-surgery IL- 6 and TNF-a serum levels were not detected in all participants. However, IL-1 $\beta$ levels significantly decreased after surgery (49.58pg/mL (18.50-112.20)-before surgery $v s 13 \mathrm{pg} / \mathrm{mL}$ (5.43-22)-after surgery, $\mathrm{p}=0.019)$. IL-6 concentrations were significantly higher in subjects who received opioid-containing anesthesia (with fentanyl) compared to subjects with opioid-free anesthesia $(224.5 \mathrm{pg} / \mathrm{mL}(186.3-262.8) \mathrm{vs} 99.5 \mathrm{pg} / \mathrm{mL}$ (60.8-138.2), respectively, $\mathrm{p}<0.001$; adjusted by age, gender, and $\mathrm{BMI})$. In addition, the use of opioids confers an increased risk for higher IL-6 levels in obese patients (OR=2.95, 95\% Cl: 1.2-7.2, $p=0.010)$. A linear regression model showed that the operative time (in hours) of bypass surgery and anesthetic technique were positively correlated with IL-6 levels.

Conclusion: Anesthesia with opioids was positively related to IL-6 serum levels in obese patients undergoing bypass surgery. This finding could have clinical relevance when choosing an appropriate anesthetic management plan for bariatric surgical patients.

Trial registration: The study was retrospectively registered at ClinicalTrials.gov Identification Number: NCT04854252, date 22/04/2021.

\section{Background}

Obesity is a multifactorial disease caused by an imbalance between daily energy intake and energy expenditure. It has been associated with low-grade chronic inflammation and comorbidities, such as type 2 diabetes mellitus, cardiovascular diseases, and hyperlipidemia[1]. Furthermore, obesity is a significant 
public health problem that affects $40.2 \%$ of women and $30.5 \%$ of men in Mexico[2], and over 500 million adults worldwide [1].

Weight loss surgery has been shown to be an effective treatment for obesity and secondary comorbidities [3]. However, the interindividual variability of adipose tissue distribution and the presence of comorbidities, increase the risk of surgical complications in these patients. Therefore, perioperative care and the type of anesthesia represent a great challenge for obese patients [4]. Although efforts have been made to develop standardized guidelines or protocols for anesthetic care in patients with obesity [5], an ideal anesthesia technique or drug combination are still unknown [4].

Total intravenous anesthesia (TIVA) is a technique where anesthesia is exclusively administered intravenously or in combination with medication in the absence of any inhaled anesthetic agents [6]. The main drugs used in TIVA are thiopental, morphine, fentanyl, ketamine, dexmetomidine, propofol, and midazolam; being fentanyl and morphine, synthetic and natural opioids, respectively. On the other hand, opioid-free anesthesia (OFA) is a technique in which no intraoperative systemic, neuraxial, or intracavitary opioid is administered. The prevention and reduction of risks associated with the use of opioids such as respiratory depression, central muscle rigidity, pharyngeal muscle weakness, negative inotropism, nausea, vomiting, constipation, urinary retention, drowsiness, and hyperalgesia, among others, supports the use of OFA in patients undergoing bariatric surgery [7].

Since obesity produces low-grade chronic inflammation, which is also associated with an increase of circulating pro-inflammatory factors, it has been reported that anesthetic agents can modulate the altered immune function in patients with obesity [4]. The opioid-mediated immune activity can have an immunosuppressive, immunostimulant, or dual effect [8]. The mechanisms involved include direct action on inflammatory cells by altering cytokine release,[9] cytokine receptor expression,[10] phagocytosis or cytotoxic actions,[11] and transcription or translation of protein mediators [12]. Hence, there is a need for further research on the immune response of patients exposed to different anesthetic drugs. Therefore, the aim of this study was to compare the effect of opioid-containing anesthesia (OCA) vs OFA on IL-6, IL-1 $\beta$ and TNF-a serum levels before and after surgery in patients with obesity undergoing bypass surgery using the Cortínez-Sepúlveda model.

\section{Methods}

The study was approved by the Ethics Committee for Human Research of the Civil Hospital of Guadalajara "Dr. Juan I Menchaca" (Registration number: 17CI14 039116 COFEPRIS). Written informed consent was obtained from all subjects after they were informed about the research procedures. The trial was retrospectively registered prior to patient enrollment at clinicaltrial.gov (NCT04854252, MartínezLópez E, PhD, 22/04/2021). Besides, the study was conducted in accordance with the Declaration of Helsinki (2013) guidelines. This manuscript adheres to the applicable Enhancing the quality and Transparency of Health Research (EQUATOR) guidelines. 


\section{Sample size and randomization}

The sample size was determined by using the formula for estimating the difference in effect using preliminary data obtained in our hospital and reported previously in literature [13] with the following assumptions: a of 0.05 (two-tailed), power of $90 \%$, Za of 1.96 (according to the normal distribution at a confidence level of 95 ), and $Z \beta$ of 1.282 (value equivalent to $\beta=0.10$ with a power of $90 \%$ ). Therefore, $a$ minimum of 15 patients per group was calculated. However, a formula for the correction for losses or abandonments was used, then a minimum of 19 patients per group was considered. Patients who met the inclusion criteria were recruited and simple 1:1 randomized by L.R.P.

\section{Study subjects}

In this randomized cross-sectional study, a total of 40 unrelated adults aged 18 -65 years from western Mexico who were scheduled for bypass surgery at the Service of Anesthesiology and Bariatric Surgery of the Civil Hospital of Guadalajara "Dr. Juan I Menchaca", Jalisco, Mexico, were recruited. The past medical history of study subjects was assessed. The inclusion criteria were: patients aged 18 to 60 years, with a $\mathrm{BMI}>30 \mathrm{~kg} / \mathrm{m}^{2}$, who were scheduled to undergo a gastric bypass, have undergone an integrated preoperative evaluation and who have signed the informed consent. The exclusion criteria were: patients with a history of ischemic heart disease, history of drug abuse, and with any known allergy to any of the drugs used during anesthesia. Elimination criteria were: patients who withdrew their consent or with insufficient and poor quality blood samples (coagulated) or other reasons that did not allow sample processing.

\section{Anthropometric variables}

Anthropometric parameters were measured after an 8-10 hour overnight fast. Measurements were performed with light clothes and without shoes. Height measurement was determined using a stadiometer with a precision of $1 \mathrm{~mm}$ (Rochester Clinical Research, Inc., Rochester, NY, USA). Body mass was determined to the nearest $0.05 \mathrm{~kg}$ using a balance scale (Seca 703; Seca, Hamburg, Germany) with subjects in underwear. Body mass index (BMI) was calculated as $\mathrm{kg} / \mathrm{m}^{2}$ and interpreted according to WHO specifications where subjects with a BMI of $30-34.9 \mathrm{~kg} / \mathrm{m}^{2}$ were considered as type I obesity, a BMI of $35-39.9 \mathrm{~kg} / \mathrm{m}^{2}$ as type II obesity, and $\geq 40 \mathrm{~kg} / \mathrm{m}^{2}$ as obesity type III [14].

\section{Anesthesia management}

\section{TIVA opioid-containing anesthesia}


Before the laparoscopic Roux-en-Y gastric bypass (LRYGB), as a bariatric procedure, subjects were randomly assigned to the study groups of anesthesia with or without an opioid. The general anesthesia technique was defined as a combination of medications administered intravenously in the absence of any inhaled anesthetic agent. Patients undergoing OCA received the following medication schedule:

Loading dose: fentanyl in a bolus dose of $3 \mathrm{mcg} / \mathrm{kg}$ (corrected weight), propofol 2-2.5 Cp by targetcontrolled infusion (TCl) with the Cortínez-Sepúlveda pharmacokinetic model (real weight)[15], ketamine $0.15 \mathrm{mg} / \mathrm{kg}$ (corrected weight), lidocaine $2 \% 1 \mathrm{mg} / \mathrm{kg}$ (corrected weight), magnesium sulfate $30-50 \mathrm{mg} /$ $\mathrm{kg}$ (corrected weight), and rocuronium bromide in a bolus dose of $0.6 / \mathrm{kg}$ (real weight).

Maintenance dose: fentanyl 0.003-0.006 mcg/ $\mathrm{kg} /$ minute (corrected weight), propofol 2-2.5 $\mathrm{Cp}$ with the Cortínez-Sepúlveda pharmacokinetic model (real weight)[15], ketamine $0.15 \mathrm{mg} / \mathrm{kg} /$ minute (corrected weight), lidocaine $2 \% 1 \mathrm{mg} / \mathrm{kg}$ (corrected weight), magnesium sulfate $10 \mathrm{mg} / \mathrm{kg} /$ minute (corrected weight), and rocuronium bromide $1.25 \mathrm{mcg} / \mathrm{Kg} /$ minute (corrected weight).

\section{TIVA opioid-free anesthesia}

TIVA opioid-free anesthesia technique is defined as a combination of medications administered intravenously in which no intraoperative systemic, neuraxial or intracavitary opioid is administered during anesthesia and it also avoids opioids in the perioperative period. Patients undergoing OFA received the following medication schedule:

Loading dose: dexmedetomidine $1-1.5 \mathrm{mcg} / \mathrm{kg}$ (corrected weight) for 40 minutes, propofol 2.5-3.5 $\mathrm{Cp}$ with the Cortínez-Sepúlveda pharmacokinetic model (real weight)[15], ketamine $0.15 \mathrm{mg} / \mathrm{kg}$ (corrected weight), lidocaine $2 \% 1 \mathrm{mg} / \mathrm{kg}$ (corrected weight), magnesium sulfate $30-50 \mathrm{mg} / \mathrm{kg}$ (corrected weight), and rocuronium bromide in a bolus dose of $0.6 / \mathrm{kg}$ (real weight).

Maintenance dose: dexmedetomidine 0.3- $0.7 \mathrm{mcg} / \mathrm{kg} /$ minute (corrected weight), propofol 2-4 Cp with the Cortínez-Sepúlveda pharmacokinetic model (real weight), ketamine $0.15 \mathrm{mg} / \mathrm{kg} /$ minute (corrected weight), lidocaine $2 \% 1 \mathrm{mg} / \mathrm{kg}$ (corrected weight), magnesium sulfate $10 \mathrm{mg} / \mathrm{kg} /$ minute (corrected weight), and rocuronium bromide $1.25 \mathrm{mcg} / \mathrm{kg} /$ minute (corrected weight).

All patients were reverted from deep rocuronium-induced neuromuscular blockade with sugammadex at a dose of 2-4 mg / kg (corrected weight) in train-of-four (TOF) monitoring.

Besides, TCl calculated with the Cortínez-Sepúlveda pharmacokinetic model was performed with Syramed® SP6000 Premium Syringe Pump (Arcomed AG, Switzerland).

\section{Depth of anesthesia monitoring}


To assess the depth of anesthesia and state of consciousness, indicators of hypoxia and brain death, the Spectral Edge Frequency (SEF) of processed real-time electroencephalography (EEG) was used during surgery.

\section{Primary outcome}

Basal and post-surgery serum levels of IL-1 $\beta$, IL-6 and TNF-a.

\section{Secondary outcomes}

Post-surgery pain estimation.

Post-surgery Adverse effects.

\section{Cytokine measurements}

Blood samples were taken before and immediately after surgery in a Vacutainer ${ }^{\circledR}$ tube and then centrifuged for 15 minutes at $3500 \mathrm{rpm}$ at $4^{\circ} \mathrm{C}$ to obtain the serum, then, samples were stored at $-80^{\circ} \mathrm{C}$ until analysis. Cytokine serum levels were measured with an enzyme-linked immunosorbent (ELISA) assay. LEGEND MAX ${ }^{\mathrm{TM}}$ Human IL-1 $\beta$ (cat \# 437007), LEGEND MAX ${ }^{\mathrm{TM}}$ Human IL-6 (cat \# 430507) and LEGEND MAX' ${ }^{\text {TM }}$ Human TNF-a (cat \# 430207) ELISA kits were used according to the supplier's instructions.

\section{Pain assessment}

After $24 \mathrm{~h}$ of surgery and with a numerical pain rating scale (NPRS), patients were asked to circle the number between 0 and 10 that best fits their pain intensity where 0 represented "no pain at all" and 10 "the worst pain ever" [16]. Therefore, there were 11 possible answers between 0-10.

\section{Adverse effects}

Regarding adverse effects, nausea and vomiting were reported after $24 \mathrm{~h}$ after surgery.

\section{Statistical Analysis}

The Shapiro Wilk test was used to analyze normal distribution of quantitative variables. Crude means or medians between groups were compared using Student's t-test or a Mann-Whitney U test, respectively. The general univariate linear model adjusted for other quantitative variables was used to compare 
differences between the two study groups. Moreover, a chi-square test was used to compare two categorical variables. To determine if the presence of one of the variables behaves as a risk factor for higher cytokine levels, an odds ratio (OR) test was performed. Regarding the evaluation of the individual and joint effect of two or more factors on a quantitative dependent variable, a linear regression model was carried out. The analysis plan was developed before accessing the data.

Statistical analyses were performed using the Statistical Package for the Social Sciences (SPSS), version 20.0 software (IBM Corp., Armonk, NY, USA). A confidence interval of $95 \%$ was set and a $p<0.05$ was considered statistically significant.

\section{Results}

\section{Population description}

Forty subjects were recruited and included in this study from November 2020 to March 2021, six men and 34 women with a mean age of $37.9 \pm 10.6$ years (Figure 1$)$. Fifty percent $(n=20)$ of subjects received OFA, while the other half received OCA, specifically fentanyl. The values of SEF ranged between 15 and 10 (data not shown), so there was no data of suppression or brain death in any of the patients during surgery. In turn, no cases of infection, mortality, readmission, or the need for additional surgery occurred in any of the study groups.

It should be noted that pre-surgery serum IL-6 levels were not detected. On the other hand, when comparing the concentrations of IL-1 $\beta$ in pre-surgery and post-surgery subjects, significant differences were found (49.58 pg/mL (18.50-112.20) vs $13 \mathrm{pg} / \mathrm{mL}$ (5.43-22) respectively, $\mathrm{p}=0.019)$. Other descriptive variables are shown in Table 1. Regarding TNF-a, concentrations were also not detected before or after surgery in all study subjects. 


\section{Table 1}

\section{Characteristics of study subjects}

\begin{tabular}{|c|c|}
\hline Variables & $(n=40)$ \\
\hline $\mathrm{BMI}\left(\mathrm{kg} / \mathrm{m}^{2}\right)$ & $43.7 \pm 6.2$ \\
\hline OB I n (\%) & $11(27.5 \%)$ \\
\hline OB II n (\%) & $29(72.5 \%)$ \\
\hline IL-6 post-surgery (pg/mL) & $162.7 \pm 106.5$ \\
\hline IL- $\beta$ pre-surgery (pg/mL) & $49.58(18.50-112.20) \star$ \\
\hline IL-1 $\beta$ post-surgery $(\mathrm{pg} / \mathrm{mL})$ & $13(5.43-22) *$ \\
\hline Operative time (hours of surgery) & $4.7 \pm 0.78$ \\
\hline NPRS & $0(0-3)^{\star}$ \\
\hline Nausea, n (\%) & $8(20 \%)$ \\
\hline Vomiting, n (\%) & $3(7.5 \%)$ \\
\hline \multicolumn{2}{|c|}{$\begin{array}{l}\text { BMI: body mass index, IL-6: interleukin 6, IL-1ß: interleukin } 1 \beta, \text { NPRS: Numerical Pain Rating Scale. } \\
\text { * Data expressed in median and interquartile range }\end{array}$} \\
\hline \multicolumn{2}{|c|}{$\begin{array}{l}\text { haracteristics of study subjects by anesthetic technique } \\
\text { en comparing the variables of subjects classified by anesthetic technique, IL-6 concentrations were } \\
\text { nificantly higher in subjects who received OCA compared to subjects with OFA (224.5 (186.3-262.8) } \\
\mathrm{mL} \text { vs } 99.5 \text { (60.8-138.2) pg/mL, respectively, p<0.001; adjusted by age, gender, and BMI). In addition, } \\
\text { ients who received OCA were } 2.9 \text { times more likely to have higher levels of IL-6 (OR=2.95, } 95 \% \mathrm{Cl} \text { : } 1.2- \\
\text { p=0.010). The other variables are shown in Table } 2 \text {. }\end{array}$} \\
\hline
\end{tabular}


Table 2

Characteristics of study subjects by anesthetic technique

\begin{tabular}{|c|c|c|c|}
\hline Variables & $\begin{array}{l}\text { Opioid-containing anesthesia } \\
(n=20)\end{array}$ & $\begin{array}{l}\text { Opiod-free anesthesia } \\
(n=20)\end{array}$ & $P$ value \\
\hline Age (years) & $37 \pm 10.3$ & $38.8 \pm 11.1$ & $0.6^{\square}$ \\
\hline Women (n) & 15 & 19 & $0.18^{*}$ \\
\hline Men (n) & 5 & 1 & \\
\hline $\mathrm{BMI}\left(\mathrm{kg} / \mathrm{m}^{2}\right)$ & $45(42.1-47.9)$ & $42.4(39.5-45.3)$ & $0.211^{\rrbracket}$ \\
\hline OB I (n) \% & $1(5 \%)$ & $10(50 \%)$ & \multirow[t]{2}{*}{$0.003^{*}$} \\
\hline OB II (n) \% & 19 (95\%) & $10(50 \%)$ & \\
\hline IL-6 post-surgery $(\mathrm{pg} / \mathrm{mL})$ & $224.5(186.3-262.8)$ & $99.5(60.8-138.2)$ & $<0.001^{\square}$ \\
\hline IL-1 $\beta$ pre-surgery $(\mathrm{pg} / \mathrm{mL})$ & $101.2(51.9-254.3)$ & 231.6 (48.3-414.9) & $0.281^{\llbracket}$ \\
\hline IL-1 $\beta$ post-surgery $(\mathrm{pg} / \mathrm{mL})$ & $15.7(3.3-28)$ & $14.86(4.5-25.2)$ & $0.921^{\rrbracket}$ \\
\hline NPRS & $1.4(0.4-2.4)$ & $1.7(0.7-2.7)$ & $0.665^{\rrbracket}$ \\
\hline Nausea, n (\%) & $6(30 \%)$ & $2(10 \%)$ & $0.2^{\star}$ \\
\hline Vomiting, n (\%) & $3(15 \%)$ & $0(0 \%)$ & $0.2^{*}$ \\
\hline
\end{tabular}

BMI: body mass index, IL-6: interleukin 6, IL-1ß: interleukin 1 beta, NPRS: Numerical Pain Rating Scale.

* Chi square test, $\square$ Values are shown as estimated means and the confidence interval, adjusted by age, gender, and $B M I$

\section{Association between operative time (hours of surgery) and anesthetic technique with serum IL-6 levels}

In a linear regression model, it was demonstrated that the operative time (hours of surgery) and anesthetic technique were positively related to IL-6 levels (Table 3). 
Table 3

Linear regression model of factors associated with serum IL-6 levels

IL-6 (pg/mL) B Coefficient $(95 \% \mathrm{Cl}) \quad \mathrm{R}^{2} \quad P$ value

$\begin{array}{llll}\text { Operative time (hours of surgery) } \quad 54(10.3-98.6) & 0.027 & 0.017\end{array}$

$\begin{array}{llll}\text { Anesthetic technique } & 81.6(18.5-144) & 0.042 & 0.013\end{array}$

\section{Discussion}

Obesity and intravenous anesthetics modulate the immune response through indirect effectors of immunity, such as cytokines [17]. Among the cytokines that are considered the most relevant biomarkers of the inflammatory response during surgical procedures are TNF-a, interleukin IL-6,and IL-1 $[18,19]$.

Besides, it is well known that morbid obesity is related to low-grade and chronic systemic inflammation and immune activation, however in this study, serum TNF-a concentrations were not detected before or after (fasting state) the surgery. This finding could be related to the fact that proinflammatory cytokines like TNF- $\alpha$, TGF- $\beta$, IL-1, IL-6, IL-8, IL-10, IFN- $\gamma$, haptoglobin, complement factors, chemoattractant cytokines, and some hormones (like leptin), are synthesized and released in human adipose tissue[20]. Therefore, future studies should consider measuring cytokines as well as their expression in adipose tissue to elucidate the mechanisms involved in the immune response of obese population.

Nevertheless, a study where fasting serum TNF-a was measured by an ELISA assay in 15 patients with android obesity, 13 patients with gynoid obesity and 15 lean healthy controls with normal glucose tolerance and blood pressure, reported higher TNF- $a$ concentrations in subjects with android obesity $(8.92 \pm 0.44 \mathrm{pg} / \mathrm{mL}, \mathrm{p}<0.01$ compared to controls) compared with gynoid obesity $(7.01 \pm 0.30 \mathrm{pg} / \mathrm{mL})$ and lean controls $(6.88 \pm 0.26 \mathrm{pg} / \mathrm{mL})$, concluding that TNF-a may be one of the factors that contributes to vascular dysfunction in subjects with android obesity[21].

Regarding IL-6, it is considered one of the most important pro-inflammatory interleukins produced by monocytes and macrophages. IL- 6 is critical in the development of the acute phase response during inflammation [22]. In addition to its role in the inflammatory response, IL-6 is vital in host defense, immune responses, wound healing, and hematopoiesis [23, 24]. Serum IL-6 levels have been shown to change during surgical procedures (in response to trauma) as well as during anesthesia. In this study, serum IL-6 levels at the preoperative level could not be detected in study subjects, however, after surgery, serum levels were higher in patients with opioid anesthesia, which is in accordance with findings by $\mathrm{H} \varnothing$ gevold HE, et al. where serum IL-6 levels increased rapidly after total hip replacement surgery, concluding that IL-6 levels are indicators of the extent of tissue damage [25].

In the present study a positive association between serum IL-6 concentration and TIVA opioid-containing anesthesia was found. In this sense, Yong-Min Liu et. al., evaluated the effects of tramadol on the proinflammatory responses in a rat model and they found that serum IL-6 levels increased 2 hours after 
the administration of anesthesia ( $40 \pm 5 v s 100 \pm 5 \mathrm{pg} / \mathrm{ml}, \mathrm{p}<0.01)$ [26]. Therefore, they suggested that IL6 serum levels could be a useful marker of tissue damage because it has been reported that IL- 6 correlates with surgery time, trauma degree, and clinical post-surgery complications $[27,28]$. Moreover, in a study conducted in 16 women undergoing abdominal hysterectomy, IL- 6 concentrations increased significantly in serum 2 hours after administering $15 \mathrm{mg} / \mathrm{kg}$ of fentanyl [3.5 (3.5-3.7) vs 40.3 (17.745.7) $\mathrm{pg} / \mathrm{mL} \mathrm{p}<0.01$ ] [29]. This study also found that the operative time (hours of surgery) is decisive for serum concentrations of IL-6. In this regard, serum levels of this cytokine have shown a positive correlation with the time of surgery $(r=0.554, p<0.01)$ and the amount of blood lost during surgery $(r=$ $0.427, p<0.01)$ since IL-6 is an important mediator in response to trauma[16]. Previous studies have shown that IL-6 and other interleukins can be useful as predictive factors that can identify patients at risk for postoperative complications [30], since it has been described as a good predictor of further morbidity and mortality [31], cardiac complications and shorter duration of mechanical ventilation [32].

Regarding pre-surgery and post-surgery IL-1 $\beta$ serum concentrations in all study subjects, significant differences were found since values obtained after surgery were lower for both study groups $(p=0.029)$. This differs from clinical studies where IL-1 $\beta$ concentrations did not change during and after the conclusion of abdominal surgery [33]. Nonetheless, an increase in IL-1 $\beta$ concentration has been reported 48 hours after surgery when using ketamine as an anesthetic [13]. IL-1 $\beta$ is expressed in macrophages, NK cells, monocytes, and neutrophils [34] and is a potent pro-inflammatory cytokine capable of inducing an adaptive cellular response in Th1 and Th17 lymphocytes. It has been also associated with exacerbation of damage in chronic diseases and tissue injuries [35].

The level of serum cytokines could be therapeutically relevant in surgical interventions. The systemic inflammatory response during and after a surgical procedure is considered an important factor for the development of postoperative complications, for instance, increased susceptibility to infection, inappropriate reactions to stress, and hypercatabolism [36, 37]. The adjustment of the immune response related to anesthesia could help reduce perioperative morbidity through the reduction of pro-inflammatory cytokines [38].

Limitations of this study include the small sample size and the absence of tissue cytokine concentration measurements. In spite of not detecting pre-surgical IL-6 values, our study highlights the differences of the inflammatory response when using OCA or OFA in patients undergoing gastric bypass, specifically, the positive association between OCA and serum IL- 6 concentrations. Therefore, further studies that measure cytokine levels and expression at various intervals before and after surgery in different tissues are needed to address the clinical significance of serum cytokine levels as markers of inflammation in the anesthetic management of patients with obesity.

Finally, it is important to note that the Cortínez-Sepúlveda model was used because it has been recently shown that it derived from the need to avoid inadequate intravenous anesthetics in obese patients with higher and anticipated plasma propofol concentrations. Cortínez et al. derived and validated a propofol model to perform effect-site $\mathrm{TCl}$ in obese patients, concluding that this model derived exclusively from 
obese patient data and is not recommended for TCl in lean patients due to the risk of underdosing [15, 39].

\section{Conclusion}

In conclusion, our results demonstrated that OCA is positively related to serum IL-6 levels in patients undergoing bypass surgery. IL- 6 serum levels may be indicator of an inflammatory response and it could be clinically relevant when choosing an appropriate anesthetic management for obese patients who undergo bypass surgery.

\section{Abbreviations}

BMI: body mass index; EEG: electroencephalography; EQUATOR: Enhancing the quality and Transparency of Health Research; LRYGB: laparoscopic Roux-en-Y gastric bypass; NPRS: numerical pain rating scale; OCA: opioid-containing anesthesia; OFA: opioid-free anesthesia; OR: odds ratio; SEF: Spectral Edge Frequency; SPSS: Statistical Package for the Social Sciences; TCI: target-controlled infusion; TIVA: total intravenous anesthesia; TOF: train-of-four.

\section{Declarations}

\section{Ethics approval and consent to participate}

The study was approved by the Ethics Committee for Human Research of the Civil Hospital of Guadalajara "Dr. Juan I Menchaca" on 01/11/2020, under the registration number: 17Cl14 039116 COFEPRIS. Written informed consent was obtained from all subjects after they were informed about the research procedures. The trial was retrospectively registered at ClinicalTrials.gov Identifier: NCT04854252, date 22/04/2021. Besides, the study was conducted in accordance with the Declaration of Helsinki (2013) guidelines. This manuscript adheres to the applicable Enhancing the quality and Transparency of Health Research (EQUATOR) guidelines.

\section{Consent for publication}

Not applicable.

\section{Availability of data and materials}

The data that support the findings of this study are available from the corresponding author, but restrictions apply to the availability of these data, which were used under license for the current study, and so are not publicly available. 


\section{Competing interests}

The authors declare that they have no competing interests.

\section{Funding}

This research was supported financially through grants from Fortalecimiento UdG (REC/CINV/0975/2019) to Erika Martínez-López.

\section{Authors' contributions}

W.C.P., L.R.P., D.G.L., and L.P.V., collected the subject's data. W.C.P., M.P.R., and E.M.L analyzed the collected data. J.J.R.V., W.C.P and M.P.R., performed the statistical analysis and laboratory experiments. L.R.P., P.S.M and J.H.M.C., were involved in planning, supervised the work and surgical processes. E.M.L designed the study and implementation of the research, to the analysis of the results and manuscript preparation. All authors read and approved the final manuscript.

\section{Acknowledgements}

The authors would like to thank the University of Guadalajara, the Civil Hospital of Guadalajara "Dr. Juan I Menchaca" in Guadalajara, Jalisco, Mexico, and the individuals who participated in this study.

\section{References}

1. Panuganti KK, Nguyen M, Kshirsagar RK. Obesity. StatPearls Publishing; 2020.

2. Encuesta Nacional de Salud y Nutrición. https://ensanut.insp.mx/encuestas/ensanut2018/index.php. Accessed 6 Apr 2021.

3. Nudel J, Sanchez VM. Surgical management of obesity. Metabolism: Clinical and Experimental. 2019;92:206-16.

4. Heil LBB, Silva PL, Pelosi P, Rocco PRM. Immunomodulatory effects of anesthetics in obese patients. World J Crit Care Med. 2017;6:140.

5. Rossaint J, Margraf A, Zarbock A. Perioperative inflammation. Anaesthesist. 2019;68:421-7.

6. Campbell L, Engbers FH KG. Total intravenous anesthesia. Anesthesia. 2001;3:109-19.

7. Sultana A, Torres D, Schumann R. Special indications for Opioid Free Anaesthesia and Analgesia, patient and procedure related: Including obesity, sleep apnoea, chronic obstructive pulmonary disease, complex regional pain syndromes, opioid addiction and cancer surgery. Best Practice and Research: Clinical Anaesthesiology. 2017;31:547-60. 
8. Liang X, Liu R, Chen C, Ji F, Li T. Opioid System Modulates the Immune Function: A Review. Transl Perioper pain Med. 2016;1:5-13.

9. Gilliland HE, Armstrong MA, Carabine U, McMurray TJ. The choice of anesthetic maintenance technique influences the antiinflammatory cytokine response to abdominal surgery. Anesth Analg. 1997;85:1394-8.

10. Schneemilch CE, Ittenson A, Ansorge S, Hachenberg T, Bank U. Effect of 2 anesthetic techniques on the postoperative proinflammatory and anti-inflammatory cytokine response and cellular immune function to minor surgery. J Clin Anesth. 2005;17:517-27.

11. Heller A, Heller S, Blecken S, Urbaschek R, Koch T. Effects of intravenous anesthetics on bacterial elimination in human blood in vitro. Acta Anaesthesiol Scand. 1998;42:518-26.

12. Loop T, Scheiermann P, Doviakue D, Musshoff F, Humar M, Roesslein M, et al. Sevoflurane inhibits phorbol-myristate-acetate-induced activator protein-1 activation in human $\mathrm{T}$ lymphocytes in vitro: Potential role of the p38-stress kinase pathway. Anesthesiology. 2004;101:710-21.

13. Roussabrov E, Davies JM, Bessler H, Greemberg L, Roytblat L, Yardeni I-Z, et al. Effect of Ketamine on Inflammatory and Immune Responses After Short-Duration Surgery in Obese Patients. Open Anesthesiol J. 2008;2:40-5.

14. Obesity. https://www.who.int/health-topics/obesity\#tab=tab_1. Accessed 6 Apr 2021.

15. Cortínez LI, Sepúlveda P, Rolle A, Cottin P, Guerrini A, Anderson BJ. Effect-site target-controlled infusion in the obese: Model derivation and performance assessment. Anesth Analg. 2018;127:86572.

16. Haefeli M, Elfering A. Pain assessment. European Spine Journal. 2006;15 SUPPL. 1:S17.

17. Hotamisligil GS. Inflammation and metabolic disorders. Nature. 2006;444:860-7.

18. Jawa RS, Kulaylat MN, Baumann H, Dayton MT. What Is New in Cytokine Research Related to Trauma/Critical Care. Journal of Intensive Care Medicine. 2006;21:63-85.

19. Cruickshank AM, Fraser WD, Burns HJG, Van Damme J, Shenkin A. Response of serum interleukin-6 in patients undergoing elective surgery of varying severity. Clin Sci. 1990;79:161-5.

20. Brandacher G, Hoeller E, Fuchs D, Weiss H. Chronic Immune Activation Underlies Morbid Obesity: Is IDO A Key Player? Curr Drug Metab. 2007;8:289-95.

21. Winkler G, Lakatos P, Salamon F, Nagy Z, Speer G, Kovács M, et al. Elevated serum TNF-a level as a link between endothelial dysfunction and insulin resistance in normotensive obese patients. Diabet Med. 1999;16:207-11.

22. Hirano T. Interleukin 6 and its receptor: Ten years later. Int Rev Immunol. 1998;16:249-84.

23. Jaber S, Amraoui J, Lefrant JY, Arich C, Cohendy R, Landreau L, et al. Clinical practice and risk factors for immediate complications of endotracheal intubation in the intensive care unit: $A$ prospective, multiple-center study. Crit Care Med. 2006;34:2355-61.

24. Kamimura D, Ishihara K, Hirano T. IL-6 signal transduction and its physiological roles: the signal orchestration model. Reviews of physiology, biochemistry and pharmacology. 2003;149:1-38. 
25. Høgevold HE, Lyberg T, Kähler H, Haug E, Reikerås O. Changes in plasma IL-1 $\beta$, TNF-a and IL- 6 after total hip replacement surgery in general or regional anaesthesia. Cytokine. 2000;12:1156-9.

26. Liu YM, Zhu SM, Wang KR, Feng ZY, Chen QL. Effect of tramadol on immune responses and nociceptive thresholds in a rat model of incisional pain. J Zhejiang Univ Sci B. 2008;9:895-902.

27. Nagahiro I, Andou A, Aoe M, Sano Y, Date H, Shimizu N. Pulmonary function, postoperative pain, and serum cytokine level after lobectomy: A comparison of VATS and conventional procedure. Ann Thorac Surg. 2001;72:362-5.

28. Raeburn CD, Sheppard F, Barsness KA, Arya J, Harken AH. Cytokines for surgeons. Am J Surg. 2002;183:268-73.

29. Taylor NM, Lacoumenta S, Hall GM. Fentanyl and the interleukin-6 response to surgery. Anaesthesia. 1997;52:112-5.

30. Kaufmann KB, Heinrich S, Staehle HF, Bogatyreva L, Buerkle H, Goebel U. Perioperative cytokine profile during lung surgery predicts patients at risk for postoperative complications-A prospective, clinical study. PLoS ONE. 2018;13.

31. Loskutov O, Maruniak S, Dryzhyna O, Malysh I, Kolesnykov V, Korotchuk N. Influence of low-opioid anesthesia in cardiac surgery on dynamics of pro-inflammatory interleukin-6. Kardiochirurgia i Torakochirurgia Pol = Polish J Cardio-Thoracic Surg. 2020;17:39. doi:10.5114/KITP.2020.94190.

32. De Gennaro L, Brunetti ND, Montrone D, De Rosa F, Cuculo A, Di Biase M. Subacute inflammatory activation in subjects with acute coronary syndrome and left ventricular dysfunction. Inflammation. 2012;35:363-70. doi:10.1007/S10753-011-9326-4/FIGURES/6.

33. Brix-Christensen V, Tønnesen E, Sørensen IJ, Bilfinger T V., Sanchez RG, Stefano GB. Effects of anaesthesia based on high versus low doses of opioids on the cytokine and acute-phase protein responses in patients undergoing cardiac surgery. Acta Anaesthesiol Scand. 1998;42:63-70.

34. Miller KM, Anderson JM. Human monocyte/macrophage activation and interleukin 1 generation by biomedical polymers. J Biomed Mater Res. 1988;22:713-31.

35. Lopez-Castejon G, Brough D. Understanding the mechanism of IL-1 $\beta$ secretion. Cytokine and Growth Factor Reviews. 2011;22:189-95.

36. Haga Y, Beppu T, Doi K, Nozawa F, Mugita N, Ikei S, et al. Systemic inflammatory response syndrome and organ dysfunction following gastrointestinal surgery. Crit Care Med. 1997;25:1994-2000.

37. Sarbinowski R, Arvidsson S, Tylman M, Öresland T, Bengtsson A. Plasma concentration of procalcitonin and systemic inflammatory response syndrome after colorectal surgery. Acta Anaesthesiol Scand. 2005;49:191-6.

38. Hsing $\mathrm{CH}$, Wang JJ. Clinical implication of perioperative inflammatory cytokine alteration. Acta Anaesthesiologica Taiwanica. 2015;53:23-8.

39. Cortínez LI, Anderson BJ. Advances in pharmacokinetic modeling: Target controlled infusions in the obese. Current Opinion in Anaesthesiology. 2018;31:415-22. 


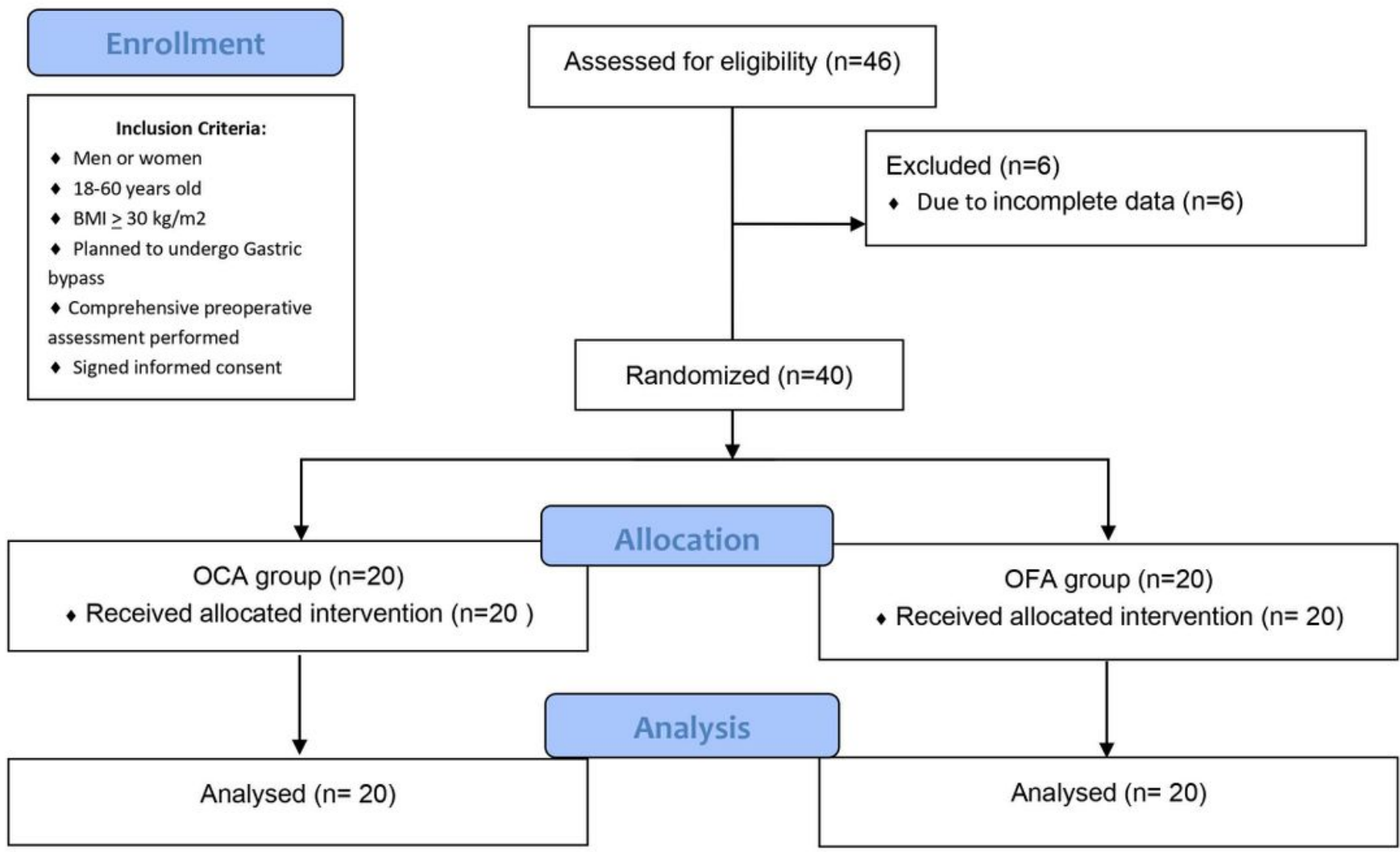

\section{Figure 1}

Flowchart of study subjects. BMI: Body Mass Index, OCA: Opiod-containing anesthesia, OFA: Opiod-free anesthesia. 